\title{
Montaje o edición: Un diseño y modelo de clasificación basado en objetivos de comunicación
}

\author{
Luis Fernando Morales Morante*
}

Recibido: 13 de abril de 2009

Aprobado: 2 de mayo de 2009

\begin{abstract}
RESUMEN
Este artículo presenta resultados de la investigación realizada por el autor como parte de su tesis doctoral. El origen de la palabra "Montaje" proviene de la ingeniería y designa el proceso de construcción de máquinas y navíos. Luego, influido por el teatro, dicho término es recogido para designar la etapa última del proceso de realización cinematográfica. Por su parte, la palabra Edición es más reciente y está restringida a la esfera del vídeo y la televisión. No obstante la funcionalidad de las definiciones existentes, el concepto nos lleva habitualmente a pensar en una labor fundamentalmente técnico-operativa. En el siguiente artículo, hacemos una reflexión acerca de la naturaleza de las definiciones de montaje y edición, sus ámbitos de aplicación creativa y de construcción de significados; y acerca de la manera cómo sus diferentes procedimientos y recursos pueden mejorar la retórica de los mensajes audiovisuales.
\end{abstract}

Palabras clave: montaje, edición, mensaje audiovisual, discurso.

\footnotetext{
Departamento de Comunicación Audiovisual y Publicidad. Universidad Autónoma de Barcelona. fernando.morales@uab.es
} 


\title{
Montage or Editing: Design and Classification Model Based on Communication Objectives
}

\begin{abstract}
This article shows the results of a research conducted by the author as part of his Ph.D. Thesis.

The origin of the word "montage" comes from engineering and indicates the process of building machinery and ships. Through the influence of theatre, such term is later used to speak about the last stage of the filmic process. As for 'editing', the word is more recent and is restricted to video and television fields. Despite the functionality of the existing definitions, the concept makes us think about a strictly technical-operating exercise. In the following paper, we reflect on the nature and definitions of 'staging' and 'editing', their fields of creative application and meaning construction. Finally, we also approach the best way how their procedures and resources can improve the rhetoric of audiovisual messages.
\end{abstract}

Key words: montage, editing, audiovisual message, discourse. 


\section{INTRODUCCIÓN}

Los términos de montaje y edición están fuertemente arraigados en la práctica de la producción y realización audiovisual y definen las partes formantes del proceso dirigido a la construcción de películas, noticias, programas de televisión y anuncios publicitarios. Dos perspectivas muy definidas han predominado en la literatura en torno a este fenómeno y sus posibles definiciones conceptuales. Una primera es la que podemos denominar "narratológica" y tiene su origen en las primeras teorías y modelos de montaje cinematográfico de la década de los treinta (Eisenstein: 1999, Balàzs: 1978) y posteriormente revisadas en los años ochenta y noventa (Reisz, 2002; Dancyger, 1999; Aumont, 1996; Martin, 1995). La segunda perspectiva es la "operacional" y se inclina por definirlos como una técnica de dominio de los instrumentos para manipular y ensamblar fragmentos de imagen y sonido (Browne, 2008, 1989; Case, 2001; Mcgrath: 2001; Barroso, 1992). No obstante la diferencia física del soporte fotosensible de la imagen y el sonido (celuloide, electrónico o digital) y la fuerte influencia de la ingeniería y la informática para determinar esta orientación, resulta evidente que los procesos de realización en el cine y el vídeo cumplen las mismas etapas y, por tanto, el montaje o la edición vienen a cumplir funciones idénticas al organizar el material interno de los discursos. Ante esta dicotomía y polémica a veces excesiva, desde la óptica mixta, académica y profesional, consideramos conveniente adoptar una postura que limite esta creciente dependencia tecnológica. Por tanto, partimos de una premisa rectora, conceptual, creativa y propia del individuo, que ubicado delante del equipo, decide qué hacer y cómo hacer cuando se enfrenta a una secuencia e intenta producir con su material un significado a veces complejo o debe resolver concretamente un problema dramatúrgico de manera exitosa, por ejemplo, con elementos escasos o defectuosos.
Pero si el montaje o la edición representan procesos polietápicos, similares e indisociables del conjunto de la realización audiovisual ¿cómo entonces podemos ser capaces de desagregar primeramente este anclaje operativo y luego determinar cada uno de sus métodos, funciones y posibles aportes a la narrativa de los mensajes? En primer lugar, analizando separadamente sus diferentes ámbitos de acción y luego interconectándolos mutuamente; así, estaremos en capacidad de definir un conjunto de categorías y métodos para ser aplicados directamente a la mejora del rendimiento de los discursos, según las necesidades específicas de nuestra comunicación. Para ello, comenzamos definiendo al montaje o la edición (según el soporte de registro del material) como un subproceso de la realización fílmica conformado por tres niveles de sujeción. Estos niveles articulan: operaciones, significaciones y métodos aplicables a la construcción de las unidades menores del discurso. Ejemplo: ensamble entre dos fragmentos o en unidades mayores: escenas, secuencias, obra terminadas $\mathrm{y}$ en cualquier género audiovisual.

\section{PRIMER NIVEL: SUJECIÓN OPERATIVA}

En primer lugar, en su nivel básico, el montaje o edición se concibe como un proceso operativo, donde el profesional interacciona directamente con una serie de imágenes y sonidos, fragmentos de celuloide o registros magnéticos que contienen los planos, tomas del rodaje y sobre los cuales va a preparar su mensaje-discurso. Aplica cuatro técnicas depurativas y organizativas elementales: selección, ordenamiento, transición y duración. Estas técnicas conllevan, a su vez unas fases o subprocesos que se interconectan directamente con funciones de comunicación. 
Tabla 1.

\begin{tabular}{|c|c|c|}
\hline TÉCNICA & FASES O SUBPROCESOS & $\begin{array}{c}\text { FUNCIÓN } \\
\text { COMUNICATIVA }\end{array}$ \\
\hline Selección & $\begin{array}{l}\text { 1. Captura, volcado del material. } \\
\text { 2. Codificación } \\
\text { 3. Minutado }\end{array}$ & $\begin{array}{l}\text { Elección del material artística y técni- } \\
\text { camente mejor logrado, para utilizarlo } \\
\text { en el armado de la pieza definitiva. }\end{array}$ \\
\hline Ordenamiento & $\begin{array}{l}\text { 1. Sucesión progresiva } \\
\text { 2. Sucesión inversa } \\
\text { 3. Sucesión alternada } \\
\text { 4. Sucesión aleatoria }\end{array}$ & $\begin{array}{l}\text { Tratamiento relacional de los } \\
\text { fragmentos con base en su producción } \\
\text { de sentido. }\end{array}$ \\
\hline Transición $\left(^{1 *}\right)$ & $\begin{array}{l}\text { 1. Corte seco: sustitución inmediata } \\
\text { de una imagen por otra. } \\
\text { 2. Fundido: oscurecimiento o apertura } \\
\text { progresiva de la imagen. } \\
\text { 3. Encadenado: sustitución progresiva } \\
\text { de una toma por otra. } \\
\text { 4. Overlapping: adelantamiento inten- } \\
\text { cional del sonido o la imagen res- } \\
\text { pecto del sonido o imagen siguien- } \\
\text { te. }\end{array}$ & $\begin{array}{l}\text { 1. Remarca el cambio visual o sono- } \\
\text { ro. } \\
\text { 2. Incorpora recursos visuales al } \\
\text { discurso. } \\
\text { 3. Construye la impresión de con- } \\
\text { tinuidad o discontinuidad espa- } \\
\text { cio-temporal. }\end{array}$ \\
\hline Duración & $\begin{array}{l}\text { 1. Fijación del punto de inicio. } \\
\text { 2. Fijación del tiempo de exposición } \\
\text { del contenido. } \\
\text { 3. Fijación del punto de salida. }\end{array}$ & $\begin{array}{l}\text { 1. Dosificar la información } \\
\text { 2. Construir relaciones rítmicas } \\
\text { entre los planos. }\end{array}$ \\
\hline
\end{tabular}

Fuente: elaboración propia.

Como se observa, este primer nivel de sujeción hace referencia exclusivamente a la secuencia de cuatro acciones de carácter operativo e incluye decisiones técnicas de carácter general, que se aplican obligatoriamente en el armado de cualquier tipo de producto. No obstante, en la columna derecha se define un listado específico de funciones comunicativas que se despliegan simultáneamente con la acción operacional, conectándola directamente con determinados componentes clave para mejorar la claridad narrativa del discurso. Hasta este momento el montaje adquiere valor sólo en la medida en que estos pasos determinan una manipulación de los materiales para decisiones creativas posteriores.
La tarea del montaje implica también intervenir en la organización del material, para controlar el diseño del espacio y el tiempo, y hacer más digerible y eficaz la representación estética audiovisual. Como parte de esta misión, el manejo de la duración de los fragmentos (Morales, 2001, p.15, 82) regula intencionalmente el suministro de la información visual y/o sonora en el interior del mensaje. Expone o suprime directamente datos y referentes clave para el procesamiento y comprensión de la información que sirven, al mismo tiempo, para despertar un interés activo por el desarrollo de las acciones mostradas. Estos procedimientos se resumen en tres posibilidades recreativas específicas. 
Tabla 2.

\begin{tabular}{|l|l|l|}
\hline \multicolumn{1}{|c|}{ PROCEDIMIENTO } & \multicolumn{1}{|c|}{ DESCRIPTOR } & \multicolumn{1}{|c|}{ FUNCIÓN COMUNICATIVA } \\
\hline Añadir/Eliminar & $\begin{array}{l}\text { Modifica los criterios de selección se- } \\
\text { gún objetivos comunicativos o por exi- } \\
\text { gencias externas. Determina qué se ve } \\
\text { y qué se oculta al espectador. }\end{array}$ & Controla el suministro de información. \\
\hline Acortar/Expandir & $\begin{array}{l}\text { Aumenta o disminuye el tiempo de } \\
\text { duración de los fragmentos y de la ac- } \\
\text { ción. }\end{array}$ & $\begin{array}{l}\text { Recrea el desarrollo de la secuencia, } \\
\text { ajustando a parámetros temporales. }\end{array}$ \\
\hline Sintetizar & $\begin{array}{l}\text { Condensa temática y argumentalmen- } \\
\text { te el contenido de la secuencia. }\end{array}$ & $\begin{array}{l}\text { Extrae sistemáticamente la información } \\
\text { relevante del desarrollo de la acción. }\end{array}$ \\
\hline
\end{tabular}

Fuente: elaboración propia.

\section{POSIBILIDADES DE MONTAJE}

Orientadas a ensamblar y recrear el discurso audiovisual en su forma y sentido integral, manipulando el tiempo de exposición de las imágenes y sonidos formantes de la serie. Cada procedimiento posee una función comunicativa específica; así tenemos:

Estas dos primeras tablas representan la instancia elemental del montaje o edición. En ellas solo se incluyen funciones asociativas elementales, no se incluyen procedimientos específicos para generar relaciones de significado más complejas. Para poderlas producir hemos de ingresar a un segundo nivel de articulación: el de la intención.

\section{SEGUNDO NIVEL: SUJECIÓN INTENCIONAL}

En el segundo nivel la actividad del montaje se distancia de sus funciones técnicas y operativas elementales, y se concentra, en cambio, en la producción de efectos de sentido a través de las relaciones significativas entre los fragmentos.

Para ello, primeramente, nos abocamos en averiguar: ¿Qué buscamos crear o producir? ¿Únicamente relatar correctamente una historia? ¿Intentar trasmitir relaciones de significado? ¿Asustar para activar identificación con la trama o el personaje?

Desarrollamos tres procedimientos básicos, congruentes con las principales formas e intenciones dominantes en los mensajes mediatizados (películas de ficción, informativos, anuncios de publicidad). (Ver tabla 3).

Tabla 3.

\begin{tabular}{|l|l|l|}
\hline PROCEDIMIENTO & \multicolumn{1}{|c|}{ DESCRIPTOR } & \multicolumn{1}{c|}{\begin{tabular}{c}
\multicolumn{1}{c|}{ FUNCIÓN } \\
COMUNICATIVA
\end{tabular}} \\
\hline Narrar & $\begin{array}{l}\text { Articula un desarrollo lógico, coheren- } \\
\text { te y compresible de las acciones. }\end{array}$ & $\begin{array}{l}\text { Facilitar la transmisión de la información y } \\
\text { mejorar la comprensión del mensaje. }\end{array}$ \\
\hline Significar & $\begin{array}{l}\text { Crea ideas y conceptos nuevos con las } \\
\text { asociaciones. }\end{array}$ & $\begin{array}{l}\text { Provocar significados y conceptos nuevos } \\
\text { mediante las relaciones de los fragmentos } \\
\text { audiovisuales. }\end{array}$ \\
\hline $\begin{array}{l}\text { Motivar y } \\
\text { emocionar }\end{array}$ & $\begin{array}{l}\text { Transmitir sensaciones y motivaciones } \\
\text { de grado complejo. }\end{array}$ & $\begin{array}{l}\text { Atraer hacia la identificación, persuasión, } \\
\text { provocar risa, miedo. }\end{array}$ \\
\hline
\end{tabular}

Fuente: elaboración propia. 
Esta subdivisión puede resultar muy útil desde el punto de vista práctico en la medida que la intencionalidad de los mensajes siempre está asociada con una forma de articulación, narrativa o expresiva, que la determina y que el espectador interpreta habitualmente en el mismo sentido (Morales, 2009). Si logramos plasmar esta compatibilidad de intereses entre emisor y receptor, es razonable suponer que el mensaje funcione mejor.

Seguidamente, una vez clarificado el objetivo de comunicación, definimos el procedimiento de montaje apropiado aplicando un criterio de concordancia mutua. Para ello, se realiza un segundo análisis de los planos y se define para cada uno su grado de afinidad con la estructura dramática integral de la secuencia o del guión. Este nuevo estudio, más profundo que en las fases previas, nos sirve para determinar el sentido específico del fragmento y su pertinencia para provocar un significado en concreto. El mapa de relaciones se desglosa en nueve modalidades, elegidas según su correspondiente función narrativa o expresiva. El método narrativo constituye el ensamble más elemental y se orienta a forjar la coherencia interna y hacer eficiente la comprensión informativa del mensaje. El método expresivo constituye un nivel creativamente más elevado y surge a partir de las asociaciones significativas que se establecen entre dos imágenes o binomios relacionales, así como el significado sugerido de la lectura del conjunto de la secuencia.

\section{CLASIFICACIÓN DE MONTAJE O EDICIÓN}

En este segundo nivel nos hemos concentrado en concretar unas herramientas discursivas de montaje orientadas a perseguir unos ideales de comunicación inequívocos. Para ello, la plantilla de clasificación nos propone un marco de referencia con una lista de opciones acotadas mediante las cuales el montador podrá aplicar diferentes procedimientos para interconectar los fragmentos, dando énfasis o bien en el aspecto narrativo o en el expresivo del discurso. Por tanto, si las necesidades del discurso obligan a plasmar varias intenciones de manera simultánea, tendrá que irse nuevamente al punto inicial, para comprobar el ajuste necesario de todos los pasos (selección, orden, transición y duración) y verificar su con-

Tabla 4.

\begin{tabular}{|c|c|c|}
\hline PROCEDIMIENTO & MODALIDADES & FUNCIÓN COMUNICATIVA \\
\hline Narrativo/a & $\begin{array}{l}\text { 1. Lineal: sucesión de imágenes o escenas en } \\
\text { orden cronológico. } \\
\text { 2. Invertido: altera el orden natural, comenzan- } \\
\text { do por el final y finalizando con la principio. } \\
\text { 3. Paralelo: dos o más acciones independientes } \\
\text { se desarrollan de modo simultáneo. } \\
\text { 4. Alternado: combinación de dos acciones, } \\
\text { entre las que existe una correspondencia } \\
\text { temporal estricta que las une. }\end{array}$ & $\begin{array}{l}\text { Hilvana los hechos para narrar } \\
\text { una acción de manera secuencial } \\
\text { o variando el sentido lógico de } \\
\text { los acontecimientos expuestos. }\end{array}$ \\
\hline Expresivo/a & $\begin{array}{l}\text { 1. Semejanza } \\
\text { 2. Contraste } \\
\text { 3. Simbólico } \\
\text { 4. Métrico: duración regular del fragmento. } \\
\text { 5. Rítmico: interconexión entre imágenes y } \\
\text { sonidos. }\end{array}$ & $\begin{array}{l}\text { Genera ideas y significados aso- } \\
\text { ciados a conceptos. Una impre- } \\
\text { sión nueva, independiente del } \\
\text { propio contenido de las imáge- } \\
\text { nes para construir una asociación } \\
\text { mental. }\end{array}$ \\
\hline
\end{tabular}

Fuente: elaboración propia. 
gruencia exacta con el correspondiente objetivo y en cada uno de los casos.

\section{LA INTENCIÓN PREDOMINANTE}

La dinámica práctica del montaje en el contexto específico de la creación y realización de mensajes impone un modelo de trabajo abierto, pero encuadrado en los límites expresivos del género, formato u otros factores extradiscursivos como el público, el horario, la cadena, entre otros. En función de la sumatoria de todos estos condicionantes, el montaje, desde su espacio de actuación, va aportando y llevando a la praxis sus propias estrategias creativas y de asociación. Por ejemplo, durante el visionado puede descubrir elementos no planificados durante el rodaje e, incluso, podría replantear una decisión acerca del sentido o la ubicación del fragmento en el interior de la secuencia. No obstante, pese a estas opciones no tan frecuentes, existen unos referentes que definen de manera predeterminada su sentido o significado, sobre los cuales se trabaja, se construyen relaciones y se adoptan decisiones para imprimir un funcionamiento expresivo particular. Hablamos de un criterio de intención predominante. Nos referimos concretamente a que siempre deberá existir un componente retórico o funcional del discurso que prevalece sobre los demás. Una vez determinada la intención predominante será más sencillo organizar y modelar la serie de planos, explotando el valor expresivo o estético de las piezas individuales de trabajo, utilizando una estructura ad hoc, acorde con aquella intención predominante que deseamos transmitir o comunicar. Hemos mencionado dos clasificaciones de montaje: narrativo o expresivo, pero en la práctica ambas intenciones no funcionan de forma totalmente aislada o separadas entre sí: actúan combinadas o de forma superpuesta, pero siempre prevaleciendo marcadamente una sobre la otra. De este modo podrá surgir de manera más clara y posiblemente eficaz el significado dominante de una porción específica del mensaje.

\section{TERCER NIVEL: SUJECIÓN DE LA PERCEPCIÓN ESPACIO-TEMPORAL}

Ahora bien, una vez ejecutada la estrategia narrativa o expresiva del mensaje, se despliega en un tercer y último nivel de montaje, cuyo objetivo es reconstruir la impresión de realidad del conjunto, de toda la representación. Mientras los dos niveles de sujeción anteriores se han concentrado en la capacidad retórica del mensaje, en este nivel comprobamos su ajuste a la coherencia y verosimilitud perceptiva. Se contemplan tres procedimientos específicos: relaciones espaciales, relaciones temporales y apariencia visual.

\section{IMPRESIÓN DE COHERENCIA Y VEROSIMILITUD DISCURSIVA}

Las operaciones comprendidas en este nivel sirven, además, para consolidar o reformular las decisiones asumidas en las instancias previas: proceso e intención, para que la serie de planos sea creíble a los ojos del espectador (MARTIN, 1995, p. 149). Las relaciones arriba expuestas deben crear una poderosa conexión relato-realidad del conjunto, que la haga verosímil, en principio, como mensaje y, a su vez, como espectáculo audiovisual mediatizado. (Ver tabla 5, página siguiente)

\section{CONCLUSIONES}

Este acercamiento tríptico, mediante el cual el montaje puede manipular creativamente sus materiales es un instrumento que puede ser útil para construir los discursos o mejorar su eficacia. El necesario recorrido por las diferentes etapas tiene sentido porque sirve para evaluar directamente el valor expresivo de la imagen y el sonido, como sustancias individuales y potencialmente creativas en un contexto expresivo organizado. Por ejemplo, mediante el visionado se comprueba, en una primera 
Tabla 5.

\begin{tabular}{|c|c|c|}
\hline PROCEDIMIENTO & MODALIDADES & FUNCIÓN COMUNICATIVA \\
\hline $\begin{array}{l}\text { Relaciones } \\
\text { espaciales }\end{array}$ & $\begin{array}{l}\text { 1. Cambio de plano } \\
\text { 2. Cambio de ángulo } \\
\text { 3. Cambio de plano/ángulo } \\
\text { 4. Desplazamiento de los } \\
\text { personajes. } \\
\text { 5. Por el movimiento de cámara. }\end{array}$ & $\begin{array}{l}\text { Orientar la captación de la atención en lo- } \\
\text { calizaciones específicas de la escena. }\end{array}$ \\
\hline $\begin{array}{l}\text { Relaciones } \\
\text { temporales }\end{array}$ & $\begin{array}{ll}\text { 1. } & \text { Acción paralela } \\
\text { 2. } & \text { Acción alterna } \\
\text { 3. } & \text { Acción consecutiva } \\
\text { 4. } & \text { Hacia el pasado } \\
\text { 5. Hacia el futuro } \\
\text { 6. } & \text { Atemporal }\end{array}$ & $\begin{array}{l}\text { Conectar las líneas narrativas del mensaje y } \\
\text { organizar el flujo temporal de la exposición. }\end{array}$ \\
\hline $\begin{array}{l}\text { Relaciones de } \\
\text { apariencia visual }\end{array}$ & $\begin{array}{ll}\text { 1. } & \text { Oscuridad/claridad } \\
\text { 2. } & \text { Enfoque/desenfoque } \\
\text { 3. } & \text { Sonido nítido/distorsionado } \\
\text { 4. } & \text { Color/blanco y negro }\end{array}$ & $\begin{array}{l}\text { Activar choques y estimulaciones sensoria- } \\
\text { les. }\end{array}$ \\
\hline
\end{tabular}

Fuente: elaboración propia.

instancia, si los planos formantes del mensaje contienen atributos relevantes y útiles en un contexto de intervención colectivo. En otro nivel de planeación podemos imprimir ritmo y fluidez, y expresar con una mayor dosis de realismo ideas, conceptos, emociones y sensaciones, mediante las yuxtaposiciones expresivas y estéticas de los planos.

A través de este recorrido hemos podido señalar e interconectar los diferentes procedimientos de construcción de mensajes para el cine, la televisión o el vídeo. Esta interacción confirma el montaje o la edición de vídeo como un proceso de articulación discursiva complejo, organizado en varios niveles, donde convive una inevitable pericia técnica-tecnológica junto al dominio de la narrativa, dramaturgia y la estética visual. A todo lo largo del proceso, se crean relaciones y se aplican métodos y funciones en diferentes niveles de acción. Todo este conjunto de operaciones hace posible, siguiendo las normas de la gramática de la imagen en movimiento, organizar la información de manera coherente y conveniente en beneficio directo del rendimiento de la capacidad retórica del mensaje.
Nota:

Incluimos únicamente las transiciones visuales de uso convencional y no efectos y transiciones digitales, multipantalla, etc.

\section{Representación de los niveles de sujeción del montaje.}

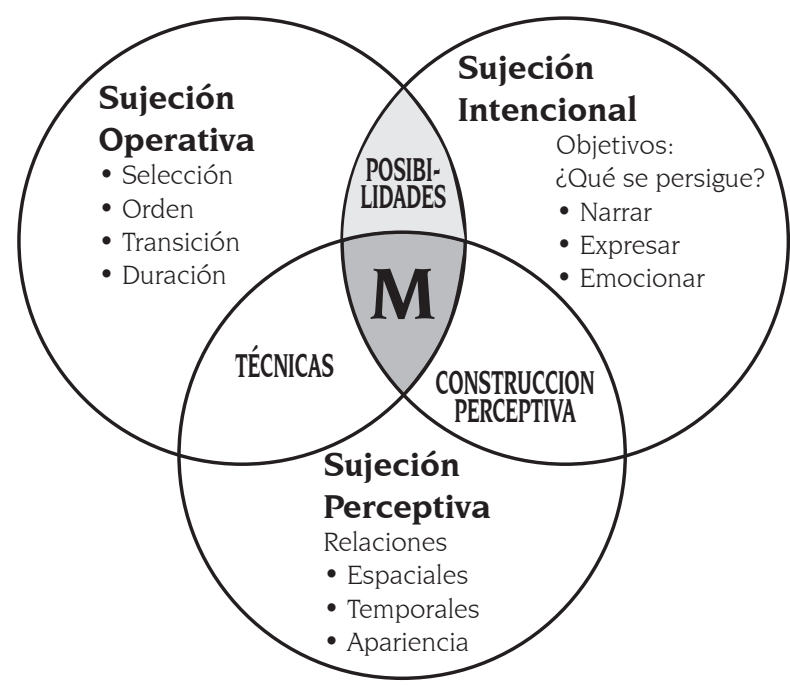

Fuente: elaboración propia. 


\section{REFERENCIAS BIBLIOGRÁFICAS}

Aumont, J. (1996). Estética del cine. Barcelona: Edit. Paidós.

Balàzs, B. (1978). Evolución y esencia de un arte nuevo. Colección Mundo Visual. Barcelona: Edit. Gustavo Gili.

Barroso, J. (1992). Introducción a la realización televisiva. Madrid: Edit. IORTV.

Browne, S. (2008). Postproducción en alta definición. Edición y finalización del vídeo en HD Amsterdam: Elsevier.

Browne, S. (1989). El montaje en la cinta de vídeo: Factor básico en la post-producción. Madrid: Edit. IORTV.

Case, D. (2001). Film technology in post production. Oxford: Focal Press.

Dancyger, K. (1999). Técnicas de edición de cine y vídeo. Barcelona: Edit. Gedisa.

Eisenstein, S. (1999). Métodos de montaje. La forma del cine. Madrid: Edit. Siglo XXI.

Martin, M. (1995). El lenguaje del cine. Barcelona: Edit. Gedisa.

Mcgrath, D. (2001). Montaje E postproducción: cine. Madrid: Edit. Océano.

Morales, F. (2009). La fusión audiovisual y su relación con la captación de la atención de los mensajes. Razón y Palabra, No 67, ISTM, Monterrey, México. En: http://www.razonypalabra.org.mx/N/n67/varia/lfmorales.html. Recuperado el 4 de marzo de 2009.

Morales, F. (2000). Teoría y práctica de la edición en video. Lima: Edit. Universidad San Martín de Porres.

Reisz, K. E Millar, G. (2003): Técnica del montaje cinematográfico. Madrid: Plot Ediciones. 